No. 4409 May 1,1954

immense technological importance. This seems to me to be an ideal activity for the National Physical Laboratory. You will have a special laboratory designed for the purpose and will find by experience how this new technique can be applied. You will be marking a trail which it will be easier for others to follow".

Sir Lawrence then said it must appear he was claiming a finger in every pie; but ceramics are really artificial minerals, and mineral structures have long fascinated X-ray analysts. Minerals are structures of great stability and resistance to change, and these are just the qualities needed for refractories. The juxtaposition of the ceramics and X-ray sections seemed to him completely appropriate, and collaboration between them should be very fruitful. $\mathrm{He}$ concluded: "The National Physical Laboratory was founded to keep the country's standards, but it has come to have another function, that of setting standards in experimental investigation. It ought to preserve a judicial and impersonal attitude, contain equipment which is a model of its kind, and be a centre to which one can go for advice, advice which depends upon an impartial review of what is going on all over the country and a readiness to adopt the best ideas whatever their source. With its unique position it has a great part to play in the interchange of ideas and the improvement of standards".

The opening of the main door of the building was performed by Sir Lawrence using a presentation key, made in the Division, of titanium and ornamented with eight other metals, each of which represented some major research or development activity of the Division during the fifty-three years of its existence.

H. A. SLOMAN

\section{UNIMOLECULAR GAS REACTIONS}

A

MEETING to discuss the theory of gas-phase unimolecular reactions and its applications to specific reactions was held in the Department of Chemistry, University College, London, on December 4. Dr. N. B. Slater (Leeds) opened the discussion by describing his approach to the problem. If it is assumed that a molecule has a few unstable states (r) of high energy which have lifetimes $L_{r}{ }^{-1}$, then if $p_{r}$ is the probability of the $r$ th state, $\omega$ the effective collision frequency per molecule and $k$ the rateconstant,

$$
k=\sum_{r} \frac{p_{r} \omega L_{r}}{L_{r}+\omega} .
$$

At high pressures $\left(\omega \gg L_{r}\right)$ the majority of energized molecules will be deactivated, and (1) reduces to $(2)$ :

$$
k=\sum_{r} p_{i} L_{r}
$$

The reaction-rate is thus the rate at which a molecule possessing at least an energy $E_{0}$ attains a critical configuration. The critical configuration may be taken as a large extension of one of the internal co-ordinates of the molecule. Treating the latter as a classical vibrating system, it can be shown ${ }^{1}$ that the rate of reaction is given by

where

$$
k=\nu \exp \left(-E_{0} / R T\right),
$$

$$
\nu^{2}=\frac{\sum_{i} \alpha_{i}{ }^{2} \nu_{i}{ }^{2}}{\sum_{i} \alpha_{i}{ }^{2}}, \quad E_{0}=\frac{q_{0}{ }^{2}}{\sum \alpha_{i}{ }^{2}}
$$

The $\nu_{i}$ are the vibration frequencies of the molecule and $\alpha_{i}$ the amplitude factors, both of which are constants of the molecule in question; $q_{0}$ is the critical extension of the co-ordinate corresponding to decomposition, and $E_{0}$ the activation energy. No attempt is made in the theory to calculate $E_{0}$.

At low pressures the rate of dissociation becomes of the same order of magnitude as the rate of deactivation, and so (1) no longer reduces to (2). However, on the basis of the present theory, it is possible to develop from (1) an expression for $k / k_{\infty}$, the ratio of the rate at any pressure to the limiting rate at high pressure ${ }^{2}$. Calculations have shown that small molecules should show first-order kinetics only at impossibly high pressures, six or more atoms being necessary to give first-order rates below a pressure of one atmosphere. Dr. Slater showed that the rate as given by (3) and (4) is essentially repro. duced at high temperatures by a quantal treatment and that these expressions are little altered by taking account of anharmonicity of the vibrations. The relation of the theory under discussion to that of Kassel and to the transition state theory was described.

Dr. A. F. Trotman-Dickenson (Manchester) gave a critical survey of the experimental field. He stated that, in his opinion, only eight decompositions have been reasonably fully investigated over a large range of pressure, which undoubtedly exhibit quasiunimolecular behaviour : they are nitrous oxide, dinitrogen tetroxide, nitrogen pentoxide, fluorine oxide, $\mathrm{CH}_{3} \mathrm{NNCH}_{3}, \mathrm{C}_{2} \mathrm{H}_{6}$, cyclo $-\mathrm{C}_{3} \mathrm{H}_{6}$, and cyclo $-\mathrm{C}_{4} \mathrm{H}_{8}$. The last two decompositions ${ }^{3}$ provide the most straightforward examples of the dependence of a unimolecular rate-constant on pressure. . The observations could not be explained on the original HinshelwoodLindemann theory. But either the Kassel theory or the Slater theory will fit the results for cyclopropane very well, though the latter theory is much to be preferred because no arbitrary parameters are introduced. A table of the relative efficiencies of various inert gases in maintaining the rates of five reactions was shown by Dr. Trotman-Dickenson, from which it can be inferred that 'kinetic theory' collisions between two complex molecules result in an equilibrium distribution of internal energy between the molecules, whereas equilibrium is attained in only one collision in ten of nitrogen with a complex molecule.

The pyrolyses of alkyl chlorides were discussed by Dr. K. E. Howlett (Bedford College, London). Although two mechanisms-unimolecular and radical chain-have been observed, about ten compounds studied have proved to be pure unimolecular. In each case, critical pressure regions exist, and the number of degrees of freedom required to account for these are reasonable ${ }^{4}$. Inert gases, while having no effect upon the high-pressure rates, are capable in various degrees of restoring the low-pressure rate to the high-pressure value. Ethylene has been found to be the most efficient in transferring energy, and helium the least ${ }^{5}$. Further, the efficiencies appear to be of the same order as predicted by the kinetic theory, in marked distinction to the calculations of C. Zener. It is also observed that the range of efficiencies is never very great. Finally, Dr. Howlett reported that Miss A. M. Goodall has found the inhibited decomposition of trichlorethylene to be a homogeneous second-order, non-chain process, in accord with Slater's predictions for small molecules. 
Dr. F. J. Stubbs (Oxford) dealt with the pyrolysis of hydrocarbons. A limiting reaction-rate in the presence of inhibitors is observed, which is independent of the nature of the inhibitor and identified with a molecular process. The rates are found to be pressure-dependent. Two modes of decomposition are found, as typified by ethane and $n$-pentane. In the former case the activation energy is independent of pressure, and there is a single transition from second to first order as the pressure rises. In the latter case the activation energy falls as the pressure rises, and the reaction order changes from two at low pressures to one, then towards two and finally reaches one again at high pressures. For compounds like $n$-pentane, the rate can be divided into two terms each corresponding to a unimolecular reaction, one of which (predominant at low pressures) is characterized by a high $E$ and $A$, and the other (predominant at high pressures) is characterized by a low $E$ and normal $A^{6}$. In the latter case, it is suggested that the activation process is essentially confined to a C-C bond, whereas, in the former, $\mathrm{C}-\mathrm{H}$ activation is involved as well. This is assumed to give rise to a multiplicity of reaction paths, corresponding to the carbon nucleus being surrounded by $a$ mobile sheath of hydrogen atoms. The magnitude of $A$ and $E$ can be interpreted on this basis.

The pyrolysis of mercury alkyls in the presence of nitric oxide as a chain inhibitor was described by Dr. B. Gowenlock (Swansea). Under these conditions both a nitroso compound and an oxime were obtained in the products ${ }^{7}$. In the case of dimethyl mercury ${ }^{8}$ the activation energy was about $6 \mathrm{kcal}$. mole $\mathrm{e}^{-1}$ less than the energy required to break both bonds, and this is considered to be the energy required to break the first $\mathrm{Hg}-\mathrm{C}$ bond; the frequency factor was about $10^{13}$ sec. $^{-1}$. However, with di- $n$-propyl mercury ${ }^{9}$ and di-isopropyl mercury ${ }^{10}, E$ corresponded to the energy required to break the two bonds and $A$ was of the order of $10^{15}$ sec.- ${ }^{-1}$. The increase in the frequency factor corresponds with the spreading of the activation energy over two bonds.

Further evidence in this connexion was provided by Dr. E. Warhurst (Manchester). While diphenyl mercury behaves like the dipropyl mercury compounds, phenyl mercuric chloride and bromide show the same type of behaviour as dimethyl mercury. This series of compounds shows an interesting type of behaviour as the number of oscillators in the reacting molecule increases. Further evidence for frequency factors of $10^{14}-10^{16}$ sec. $^{-1}$ coupled with 'bigh' activation energies is provided by a series of carbonyl-containing compounds studied by $M$. Szwarz and his co-workers.

Dr. H. O. Pritchard (Manchester) pointed out that an explanation of the observed differences in behaviour of dimethyl mercury and di-isopropyl mercury upon pyrolysis would probably have to await a further interpretation of the vibrational spectra of mercury di-alkyls. Again, uncertainties in the strengths of $\mathrm{C}-\mathrm{H}$ bonds make it possible that the activation energy for the di-isopropyl mercury decomposition may be significantly greater than the sum of the energies required to break the two $\mathrm{Hg}-\mathrm{C}$ bonds. Such behaviour is actually observed in azomethane, where the activation energy is approximately double the sum of the dissociation energies for the two $\mathrm{N}-\mathrm{CH}_{3}$ bonds. However, in this case it is reasonable to assume that the activation energy is all concentrated in one $\mathrm{N}-\mathrm{CH}_{3}$ bond, since the frequency factor is only $10^{14} \mathrm{sec}^{-1}$.

The case of dimethyl mercury was referred to again by Dr. L. H. Long (Exeter), who reported an activation energy for the unimolecular decomposition in excellent agreement with that of Gowenlock, although obtained by a different technique. As was also noted by the previous two speakers, the frequency factor tends to rise with increasing pressure.

Dr. T. O. Hirschfelder (Wisconsin) emphasized the importance of a theoretical calculation of energy transfer at surfaces. There is strong experimental and theoretical evidence to indicate that molecules obtain their energy of activation by collision with the walls rather than with other molecules in the gas phase. This would require a considerable modification of the Slater theory and lead to somewhat different results. In connexion with the Eyring theory of bimolecular reaction-rates, Dr. Hirschfelder underlined the necessity of allowing for rotation in the activated complex. With the $\mathrm{H}_{2} \mathrm{I}_{2}$ complex, for example, unless this factor is allowed for, the rate comes out too small by a factor of about 1/300. A value in better agreement with experiment is obtained if rotation is considered. It is to be hoped that the future development of reaction-rate theory will include both unimolecular and bimolecular reactions in a uniform treatment.

Some results of experiments on the pyrolysis of alkyl bromides carried out by Drs. J. H. S. Green and P. J. Thomas and Mr. G. D. Harden were described by Dr. A. Maccoll (University College, London ${ }^{11}$. Whereas secondary and tertiary bromides decompose cleanly by a unimolecular mechanism, the primary compounds decompose by a mixed chain-unimolecular mechanism, the chain part of which, however, may be eliminated by the use of cyclohexene as an inthibitor. In all cases of unimolecular decomposition, the frequency factors are of the order of $10^{13}$ sec. $^{-1}$. An interesting series is that of the normal bromides, for which (apart from ethyl) the activation energy is constant and the rates appear to approach a limiting value as the chainlength increases.

Prof. H. C. Longuet-Higgins (King's College, London) outlined a quantal attack on the problem of reaction-rates, which he has been developing in collaboration with Mr. P. W. Higgs. In the case of a molecule capable of dissociation and which cannot be considered as being in a pure quantum state, the outward flux across a given value of a co-ordinate may be calculated. For an assembly of simple harmonic oscillators in thermal equilibrium, such a calculation leads to the quantal expression for the reaction-rate. It is found that at high temperatures (the classical limit) equation (3) is recovered, but at intermediate temperatures the rate expression departs from (3) ; in particular, a finite rate is predicted at $0^{\circ} \mathrm{K}$. It was suggested that perhaps the theoretical criterion of reaction $q>q_{0}$ would need to be reexamined in the light of the experimental criterion, which is the appearance of new chemical species. The full solution of the problem in the case of many degrees of freedom is not yet available.

The flexibility of the Eyring treatment in its ability to account for a wide variation in $v$ was referred to by Dr. B. Atkinson (Imperial College of Science and Technology, London). High value of $v$ can be interpreted in terms of a 'loosening' of the molecule in the transition state and low values in terms of a 'stiffening'. 
A number of points emerged as to the present state of knowledge of unimolecular reactions. In the first place, there now seems to be a large number of well-established gas-phase unimolecular reactions. Secondly, experimental investigations of the lowpressure region have enabled relative collision efficiencies for energy transfer to be estimated. Thirdly, there appears to be quite a wide range of frequency factors. Fourthly, it is desirable to extend the theoretical treatment along quantal lines. Finally, recognition of the possible multiplicity of reaction paths may be a fruitful line of approach.

The meeting closed with an expression of gratitude to Prof. C. K. Ingold, of University College, London, through whose interest the conference was made possible.

${ }^{2}$ Slater, N. B., Proc. Roy. Soc., A, 194, 112 (1948).

${ }^{2}$ Slater, N. B., Phil. Trans., A, 246, 57 (1953); Proc. Roy. Soc., A, 218, 224 (1953).

${ }^{3}$ Pritchard, H. O., Sowden, R. G., and Trotman-Dickenson, A. F., Proc. Roy, Soc, A, 217, 563 (1953); 218, 416 (1953).

${ }^{4}$ Howlett, K. E., J. Chem. Soc., 3695, 4487 (1952).

${ }^{5}$ Howlett, K. E., J. Soc. Chem. Indust., 1175 (1952).

- For all references see Peard, M. G., Stubbs, F. J., and Hinshelwood, C. N., Proc. Roy. Soc., A, 214, 471 (1952).

"Chilton, H. T. J., and Gowenlock, B. G., J. Chem. Soc., 3232 (1953)

${ }^{8}$ Gowenlock, B. G., Polanyi, J. C., and Warhurst, E., Proc. Roy. Soc., A, 218, 269 (1953).

' Chilton, H. T. J., and Gowenlock, B. G. (to be published). ${ }^{10}$ Chilton, H. T. J., and Gowenlock, B. G., Trans. Farad. Soc., 49,

${ }^{11}$ Green, J. H. S., Harden, G. D., Maccoll, A., and Thomas, P. J. J. Chem. Phys., 21, 178 (1953).

\section{SCIENTIFIC AND TECHNICAL DOCUMENTATION IN TURKEY}

$\mathrm{T}$

ECHNICAL Assistance projects in Turkey, some of them operating, others to come into operation if and when funds are available, cover a great variety of subjects: public administration, economic research, civil aviation, statistics, maternal and child health, diseases control, water resources development, oil resources development, fisheries development, hydrogeology, seismology, and various others. Bibliographical and documentation services, needed by many of them, are also included.

The National Bibliographical Centre is one of three Unesco projects under the Expanded Programme of Technical Assistance in Turkey. It was set up in 1952, with the assistance of two library experts : a specialist in bibliography, from France, and $a_{0}$ specialist in documentation, from the United Kingdom. The Centre is housed at the National Library in Ankara and, apart from co-operating with Technical Assistance projects, maintains close contact with government departments, university faculties, scientific societies, educational institutes, research stations, industrial undertakings and, of course, other libraries.

The main objective of the Bibliographical Centre is to assure the availability of information to all Turkish programmes for scientific, technical and economic development. This emphasis on Turkish affajrs does not, however, preclude it from collaborating in a system of international exchanges of scientific information and so render valuable service to the region, and to the world.

With financial aid earmarked for the purpose by Unesco Technical Assistance, the Centre brought together a much-needed collection of handbooks, monographs, bibliographies, catalogues and other library tools in many different languages. This useful reference library, open to bona fide research workers, has meanwhile become indispensable to staff and readers alike.

Under its regular programme, Unesco has estab. lished in Istanbul a branch office of its Middle Fast Science Co-operation Office, the headquarters of which are located in Cairo. The Istanbul Office acts as an outpost of Unesco in Turkey, and among its activities has been the ad hoc supply of scientific information requested by Turkish scientific workers. The United States Information Service offers similar facilities within the range of United States sources. The Middle East Science Co-operation Office in Cairo issues an abstracting journal in the English language which covers the Middle East countries and includes several periodicals published in Turkey.

Fuller coverage of Turkish periodicals in the pure and applied sciences, technology and so on, is now provided by "Türkiye Makaleler Bibliyografyası" ("Bibliographie des articles parus dans les périodiques turcs'), issued by the National Bibliographical Centre. It is published at irregular intervals, is arranged by Universal Decimal Classification numbers, with the titles of articles in Turkish and French, and has an author index. Translations or abstracts of specified papers, and microfilms of the original texts, are supplied on request.

As a means of meeting and co-ordinating incoming demands for foreign articles which may be available in Turkey, the Bibliographical Centre has compiled, and keeps currently up to date, a union catalogue of foreign periodicals in Turkish libraries. It is now in its second edition.

Scientific papers published in other journals are obtained as microfilms from abroad, against payment in Unesco coupons or, mostly, on an exchange basis. The first exchange arrangement was concluded in March 1953, between the National Bibliographical Centre in Ankara and the Centre National de la Recherche Scientifique in Paris. This places at the disposal of Turkish men of science a substantial part of the world's scientific literature, and makes Turkish contributions available to scientists in the West. The microfilm laboratory at the Turkish National Library, previously almost exclusively engaged on the copying of manuscripts, has adjusted itself admirably to the rew tasks, and a microfilm camera and microfilm reading machines have been imported from Britain.

Approach to documentation may be two-fold-short-term and long-term-one taking care of immediate needs and the other making provision for potential requirements. It has been the policy of the Centre to prepare for both, trying to do justice at the same time to border-line cases, of which there a.re many.

Inquiries for documentation were received from quarters interested in subjects as widely apart as : palæontological research; fish culture and fish industry ; methods of preserving and utilizing agricultural products; and industrial accidents and workmen's compensation-to mention only a few. It had, moreover, been agreed between Unesco and the World Health Organization, also represented in Turkey, that every possible help should be given to medical libraries and medical documentation in Turkey. The Bibliographical Centre was also called upon to act as liaison for a direct approach between research and study projects in Turkey and their opposite numbers elsewhere. An agricultural research 